\title{
Canadian Association of Gastroenterology Practice Guidelines: Evaluation of dysphagia
}

\author{
Alan W Cockeram MD FRCPC
}

\section{DEFINITION}

Dysphagia may be defined as difficulty in swallowing. Dysphagia may be classified as oropharyngeal or esophageal; oropharyngeal dysphagia arises from a structural or functional abnormality in the oropharynx, and esophageal dysphagia occurs as a result of structural or functional abnormalities in the esophagus.

Esophageal dysphagia may be further subclassified symptomatically as dysphagia for solids alone, which usually suggests a mechanical problem, versus dysphagia for liquids and solids, which is more suggestive of a neuromuscular problem. Dysphagia may be described by the patient as a sensation of food 'sticking' or as a sensation of food passing slowly through the esophagus. True dysphagia always indicates organic disease and always warrants investigation and consultation if no cause is found in initial studies. These symptoms should be distinguished from those of a persistent foreign body-type sensation or a sensation of a lump, which is more typical of globus sensation. Odynophagia, defined as pain with swallowing, may occur in association with esophageal dysmotility or as a result of mucosal disease in the esophagus.

\section{PHYSIOLOGY OF SWALLOWING}

Normal swallowing is accomplished by a complex series of interconnected events. After mechanical crushing of a food bolus in the mouth, the tongue forces the food bolus to the posterior oropharynx. The upper esophageal sphincter relaxes, allowing the food bolus to enter the proximal esophagus. The food bolus is then propelled down the esophagus by peristaltic contraction. As the food bolus reaches the lower esophageal sphincter, the sphincter relaxes to allow the food to progress into the stomach.

\section{SPONSORS AND VALIDATION}

This practice guideline was developed by Dr Alan W Cockeram MD FRCPC and was reviewed by

- Practice Affairs Committee (Chair Dr A Cockeram): Dr T Devlin, Dr J McHattie, Dr D Petrunia, Dr E Semlacher and Dr V Sharma

- Canadian Association of Gastroenterology (CAG) Endoscopy Committee (Chair - Dr A Barkun)

- Dr N Diamant, Dr N Marcon and Dr W Paterson

- CAG Governing Board

\section{OROPHARYNGEAL DYSPHAGIA}

The majority of cases of oropharyngeal dysphagia occur as a result of neuromuscular degeneration or damage such as a cerebral vascular accident. In addition to strokes, degenerative diseases such as amyotrophic lateral sclerosis, myasthenia gravis and Parkinson's disease are the most common neuromuscular causes. Anatomical causes are less frequent but include Zenker's diverticulum, proximal esophageal webs, strictures, tumour and, less commonly, vertebral osteophytes. A more complete listing of causes is included in Table 1 (1).

Patients with oropharyngeal dysphagia typically describe difficulty in initiating swallowing. Frequently this may be associated with regurgitation or symptoms of aspiration. Change in speech is often associated. All of these latter fea-

Hilyard Place, St John, New Brunswick

Correspondence: Dr Alan Cockeram, Hilyard Place, Building A, 270-560 Main Street, St John, New Brunswick E2K $1 J 5$.

Telephone 506-634-7742, fax 506-632-1107, e-mal acockeram@hotmail.com 
TABLE 1

Selected causes of oropharyngeal dysphagia

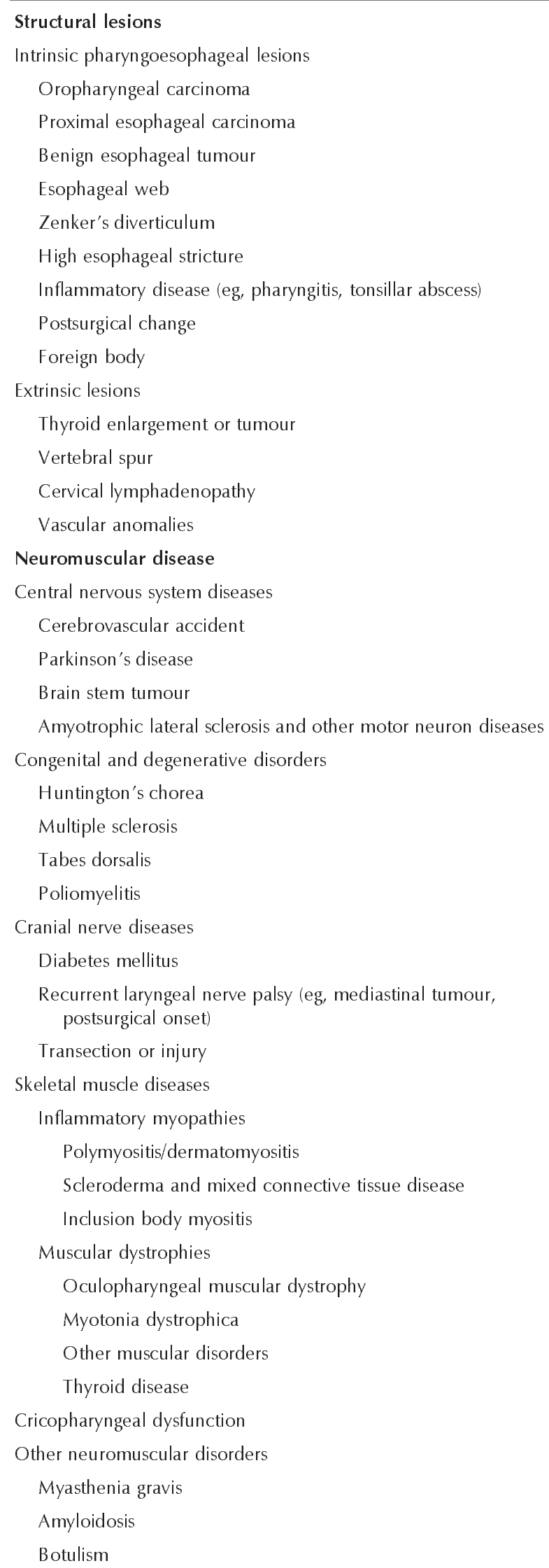

Modified from reference 1 tures suggest neuromuscular degeneration, particularly when the symptoms are progressive. Other neurological manifestations should be sought.

\section{ESOPHAGEAL DYSPHAGIA}

Patients with esophageal dysphagia typically complain of dysphagia for solids and/or liquids. Gastroesophageal reflux is a frequent cause of esophageal stricture. The majority of patients with stricturing secondary to reflux have a history of heartburn; however, this may be absent or remote in older patients and in those with Barrett's esophagus. Nausea may indicate reflux with or without gastroparesis. Typically dysphagia from reflux is slowly progressive. Intermittent dysphagia for solids suggests a Schatzki's ring. Esophageal or proximal gastric tumours often produce rapidly progressive dysphagia for solids in the absence of a history of any significant heartburn. Significant weight loss favours a neoplastic cause although weight loss may occur with esophageal dysmotility, usually at a slower pace. Localization by the patient of the site of dysphagia in the lower retrosternal area usually accurately indicates a more distal esophageal site of obstruction. More proximal localization of the site of dysphagia does not predict the true site of obstruction as accurately (2).

Dysphagia for liquids as well as solids is more suggestive of an esophageal motility disorder but solid-only dysphagia may also occur with motor disorders, often in a sporadic pattern (versus the more predictable pattern noted with mechanical causes). Patients with dysmotility may note aggravation of dysphagia with colder foods. Odynophagia may occur with esophageal dysmotility. A history of heartburn in addition to dysphagia for both solids and liquids may suggest refluxinduced dysmotility, or a disease process such as scleroderma with reflux superimposed upon esophageal dysmotility.

An alternative approach is to classify motility disorders as hypomotile versus spastic. Hypomotile disorders with decreased activity in the body and/or sphincter include scleroderma and other collagen vascular disorders. These often result in gastroesophageal reflux. Spastic motor disorders with increased contraction in the body and/or sphincter include achalasia and other motor disorders listed in the primary category in Table 2 (3). These may result in functional obstruction leading to dysphagia and/or pain.

\section{CLINICAL EVALUATION}

Patient history is critically important in evaluating dysphagia (4). The pertinent details of the history are alluded to above. Historical features that should be sought include the following:

- difficulty in initiating versus completing swallowing;

- timing of symptoms after initiating swallowing;

- other neurological symptoms, ie, voice change, drooling, aspiration and/or weakness;

- dysphagia for solids versus liquids;

- intermittent versus progressive dysphagia;

- sporadic versus predictable dysphagia; 
TABLE 2

Etiologies of esophageal dysphagia

\begin{tabular}{l} 
Neuromuscular (motility) disorders \\
Primary \\
Achalasia \\
Other primary motility disorders \\
Diffuse esophageal spasm \\
$\quad$ Nutcracker esophagus (hypertensive peristalsis) \\
Hypertensive lower esophageal sphincter \\
$\quad$ Nonspecific esophageal dysmotility \\
Secondary \\
Motor disorder secondary to reflux esophagitis \\
Scleroderma \\
Other collagen disorders \\
Chagas' disease \\
Mechanical lesions - intrinsic \\
Most common \\
Peptic stricture \\
Lower esophageal (Schatzki's) ring \\
Carcinoma \\
Other \\
Esophageal webs \\
Esophageal diverticula (often with an associated esophageal \\
Merign bodies \\
Mechanication-induced injury \\
\hline
\end{tabular}

Modified from reference 3

- history of remote or recent heartburn;

- weight loss;

- odynophagia;

- foreign body sensation; and

- prior history of any caustic ingestion.

Figure 1 provides a diagnostic algorithm for symptombased diagnosis (5).

\section{PHYSICAL EXAMINATION}

In patients with oropharyngeal dysphagia, the physician should make particular note of other neurological manifestations, such as abnormal speech pattern, drooling, other cranial nerve lesions or other more generalized motor abnormalities, eg, weakness or gait disturbance. The chest should be examined to rule out the possibility of aspiration pneumonia.

The patient with esophageal dysphagia should be carefully examined for any cervical lymphadenopathy, organo-

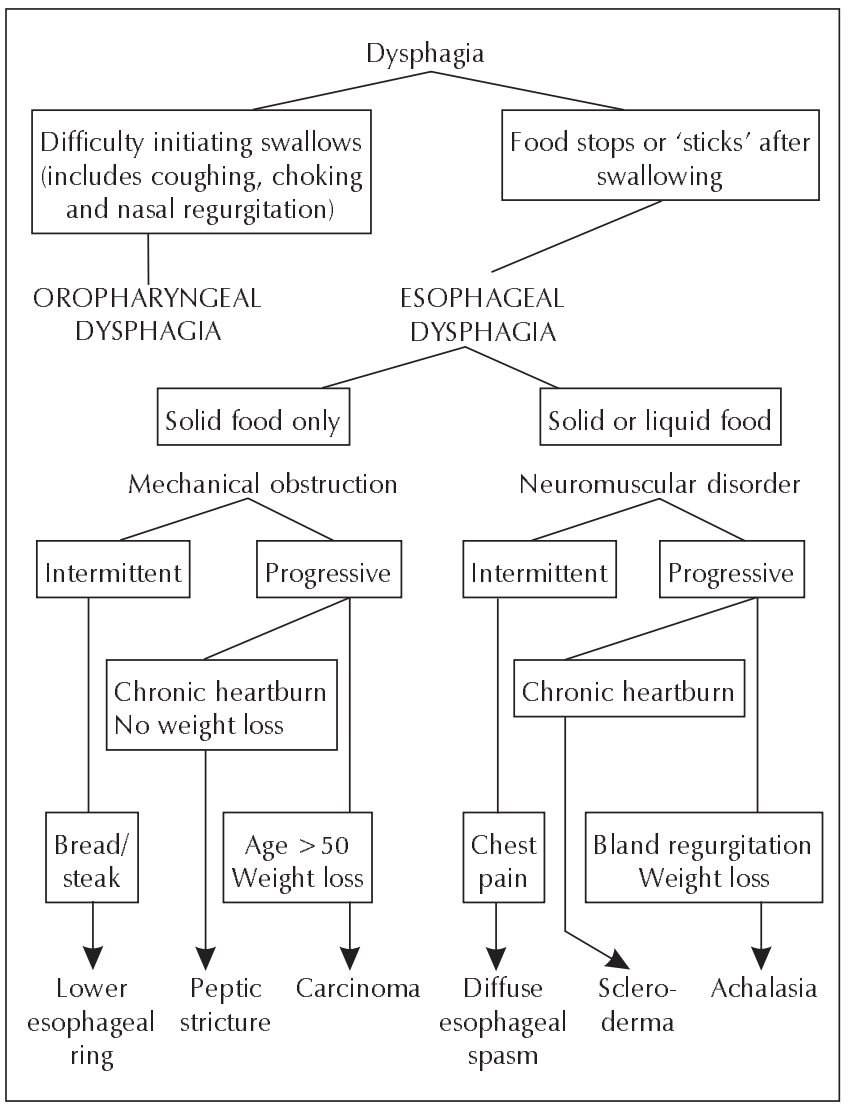

Figure 1) Algorithm for symptomaticassessment of the patient with dyspepsia. Important differentiating symptoms are within boxes. Modified and reproduced with permission from reference 5

megaly, abdominal mass and evidence of weight loss, all of which may suggest a neoplasm. Skin lesions such as telangiectasia, sclerodactyly or calcinosis may occur in association with scleroderma and esophageal dysmotility. Occasionally a succussion splash may be heard in the chest in patients with achalasia.

\section{APPROACH TO INVESTIGATION}

The screening procedures of choice classically have been an esophagram and upper gastrointestinal series, and many family physicians follow this route. However, upper gastrointestinal series can miss significant lesions, especially in early disease and particularly if the esophageal lumen is not well distended during filming. Specialized techniques may improve the sensitivity of the examination. Video studies may be more useful in evaluating esophageal dysmotility, particularly in cases of oropharyngeal dysphagia where the $\mathrm{x}$-ray is truly the only way to evaluate this area. Slow motion viewing may help to identify more minor discoordination or aspiration. After objective clinical evaluation the speech pathologist may assist the clinician in the evaluation of oropharyngeal dysphagia. Modified barium swallow using barium impregnated marshmallows or pudding may be useful. Upper gastrointestinal series is not always required first if endoscopy is to be undertaken. Certainly a negative esopha- 
TABLE 3

Manometric features of primary esophageal motility disorders

\begin{tabular}{|c|c|c|}
\hline Diagnosis & Required features & Sometimes present \\
\hline Achalasia & $\begin{array}{c}\text { Esophageal body - } \\
\text { lack of peristalsis }\end{array}$ & $\begin{array}{l}\text { Incomplete LES relaxation } \\
\text { Elevated LES pressure } \\
\quad(>45 \mathrm{mmH}) \\
\text { Elevated intraesophageal } \\
\quad \text { pressure }\end{array}$ \\
\hline $\begin{array}{l}\text { Nutcracker } \\
\text { esophagus }\end{array}$ & $\begin{array}{l}\text { Increased amplitude } \\
(>180 \mathrm{mml} / \mathrm{g}) \text { with } \\
\text { normal peristalsis }\end{array}$ & Increased duration $(>6 \mathrm{~s})$ \\
\hline $\begin{array}{l}\text { Diffuse } \\
\text { esophageal } \\
\text { spasm }\end{array}$ & $\begin{array}{l}\text { Simultaneous } \\
\text { contractions } \\
\quad>10 \% \text { wet } \\
\text { swallows) } \\
\text { Intermittent normal } \\
\text { peristalsis }\end{array}$ & $\begin{array}{l}\text { Repetitive contractions } \\
\text { Spontaneous contractions } \\
\text { Increased duration(>6 s) } \\
\text { and/or amplitude } \\
\quad(>200 \mathrm{mml} / \mathrm{g})\end{array}$ \\
\hline $\begin{array}{l}\text { Hypertensive } \\
\text { LES }\end{array}$ & $\begin{array}{l}\text { Elevated LES pressure } \\
\quad(45 \mathrm{mml}) \\
\text { Normal LES relaxation } \\
\text { Normal peristalsis }\end{array}$ & \\
\hline $\begin{array}{l}\text { Nonspecific } \\
\text { esophageal } \\
\text { motility } \\
\text { disorder }\end{array}$ & $\begin{array}{l}\text { Any combination of } \\
\text { features in } \\
\text { 'Sometimes present' } \\
\text { column }\end{array}$ & $\begin{array}{l}\text { Nonperistaltic contractions } \\
\text { Prolonged contractions } \\
(>6 \mathrm{~s}) \\
\text { Multiphasic contractions } \\
\text { Retrograde contractions } \\
\text { Low amplitude peristalsis } \\
\quad(<3 \mathrm{mmH}) \\
\text { Absent peristalsis with normal } \\
\quad \text { LES }\end{array}$ \\
\hline
\end{tabular}

LES Lower esophageal sphincter

gram should not be considered sufficient to rule out organic disease nor should it be a reason to cease investigation of the patient with persisting dysphagia.

In the patient with a significant history suggesting mechanical obstruction, endoscopy is more likely to be helpful in establishing a diagnosis because it is more sensitive in detecting mucosal lesions such as minor ulcerations and less severe changes of reflux. In addition, endoscopy offers the added benefit of biopsy and/or brushings, and offers the possibility of therapy in conjunction with the diagnostic test. If significant mechanical narrowing is identified one may proceed with dilation at the same setting. Endoscopy is quite sensitive at detecting strictures less than $10 \mathrm{~mm}$ in diameter but slightly less sensitive for wider strictures (6). Endoscopy may not detect tapered narrowing of the esophagus when the lumen is wider than the endoscope and there is no associated mucosal abnormality.

Neither endoscopy nor radiography are totally accurate in all situations and they are not interchangeable. Often the two are complementary and both are operator-dependent.

If patient history or barium studies suggest esophageal dysmotility one may choose to proceed directly with esophageal manometry, but in most cases it is preferable to proceed with endoscopy before manometry to ensure that no mechanical lesion is present. In some cases dysmotility may be related to unsuspected reflux esophagitis. Rarely esophag- eal dysmotility may arise as a result of lesions in the cardia which may be poorly identified by upper gastrointestinal series. After mechanical obstruction has been excluded one may then proceed with esophageal manometry. Several recording systems are available; discussion of the relative merits of each is outside the scope of this Practice Guideline. The typical manometric features of the major causes of motility disturbances of the esophagus are outlined in Table 3.

\section{THERAPY}

The outcome of the diagnostic procedures dictates the therapeutic approach.

Patients with oropharyngeal dysphagia may be helped by consultations with speech pathologists and dieticians and by dietary changes including predominantly soft, puréed or jellied foods and avoidance of liquids that may be aspirated. As a short term measure in patients with oropharyngeal dysphagia, nasoenteric feeding may be useful. Oropharyngeal dysphagia from cerebrovascular accidents may gradually improve with time; however, if there is no improvement after more than a month or in cases where neuromuscular degenerative disease has caused oropharyngeal dysphagia, then management with gastrostomy is indicated. Gastrostomy may be performed using several different techniques.

Patients with mechanical dysphagia arising from esophageal lesions require appropriate dilation. Benign disease usually responds to single or repeated dilations. Surgery is rarely indicated to treat the obstruction per se, although patients with severe reflux with or without a stricture may be considered for antireflux surgery. The majority of patients respond well to medical management with dilation as necessary. There is evidence that treatment with a proton pump inhibitor lessens stricture recurrence $(7,8)$.

Patients with neoplastic lesions causing stricturing require appropriate investigation to stage the disease. Surgical resection offers the only possibility of cure. If resection is not considered feasible, internal and/or external radiotherapy may be considered for squamous cell neoplasms. Chemotherapy may also be considered. Patients with unresectable disease who require frequent dilation benefit from endoprosthesis. While there is a significant risk with placement of rigid esophageal endoprosthesis, such modalities offer good palliation of symptoms. Newer expendable stents can be placed with less risk. Laser or thermal ablation of tumours are other alternatives.

Patients with esophageal dysmotility may respond to pharmacotherapy using nitrates or calcium channel antagonists, although there are no controlled trials demonstrating a benefit in motor disorders other than achalasia. Esophageal dilation is sometimes helpful. In patients with achalasia, treatment with pneumatic dilation remains the standard therapy, but in patients who would not tolerate a complication of dilation, the recent advent of botulinum toxin may offer an alternative. Current evidence suggests that the response may not be sustained. Patients failing to respond to pharmacological or endoscopic therapy may be considered for myotomy or rarely for esophagectomy. 


\section{REFERENCES}

1. Clouse RE. Gastrointestinal disease. In: Sleisenger MH, Fordtran JS, eds. Pathophysiology/Diagnosis/Management, 5th edn. Philadelphia: WB Saunders Co, 1993:341.77.

2. Kahrilas PJ. Disorders causing oropharyngeal dysphagia. In: Sleisenger MH, Fordtran IS, eds. Pathophvsiologv/Diagnosis/ Management, 5th edn. Philadelphia: WB Saunders Co, 1993:205.18

3. Bennett JR, Castell DO. The Esophagus, 2nd edn. Boston: Little Brown and Co, 1995:29.39.

4. Richter JE. Heartburn, dysphagia, odynophagia, and other esophageal symptoms. In: Sleisenger MH, Fordtran JS, eds.
Pathophysiology/Diagnosis/Management, 5th edn. Philadelphia: WB Saunders Co, 1993:331-40.

5. Castell DO, Donner MW. Evaluation of dysphagia: a careful history is crucial. Dysphagia 1987:2:65-71.

6. Ott DJ. Endoscopy sensitivity in the detection of esophageal strictures. J Clin Gastroenterol 1985;7:121-5.

7. Klinkenberg-Knol EC, Festen HP, Jansen JB, et al. Long-term treatment with omeprazole for refractory reflux esophagitis: efficacy and safety. Ann Intern Med 1994:121:161-7.

8. Marks RD, Richter JE, Rizzo J, et al. Omeprazole versus H2-receptor antagonists in treating patients with peptic stricture and esophagitis. Gastroenterology 1994;106:907-15.

\section{Canadian Association of Gastroenterology Practice Guideline Disclaimer}

This clinical practice guideline has been developed by the author on behalf of the Canadian Association of Gastroenterology (CAG) in order to outline the clinical approach to management problems or training issues. After preparation by the author, based on a review of the literature, each guideline is extensively reviewed by the CAG Practice Affairs Committee, composed of practitioners from across Canada. Changes are made, and once the guideline is felt to be appropriate, it is then circulated for further review by recognized Canadian experts and then amended further. Finally, the guideline is presented to the CAG Governing Board for further review and final approval.

Practice guidelines are intended to give an understanding of a clinical problem and outline one or more preferred approaches to investigation and management of the problem. While practice guidelines are intended to be useful to all physicians, it is recognized that specialists may rely less on practice guidelines than those in more general practice. These guidelines are intended to give a practical approach to a problem based on the current literature, but are not intended to be state-of-the-art reviews with extensive references.

Practice guidelines are developed to be of assistance to practising clinicians and are not intended to be the only approach to the management of clinical problems, nor are they intended to be considered as a 'standard of care'. The CAG Practice Affairs Committee recognizes that clinical circumstances may at times justify an approach different from that outlined in a practice guideline. It is also recognized that new developments in medical research and clinical practice may require subsequent changes to the practice guideline. 


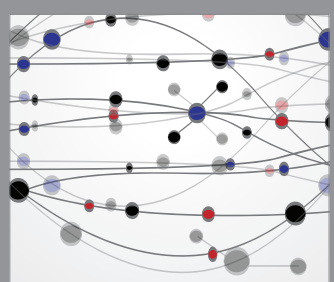

The Scientific World Journal
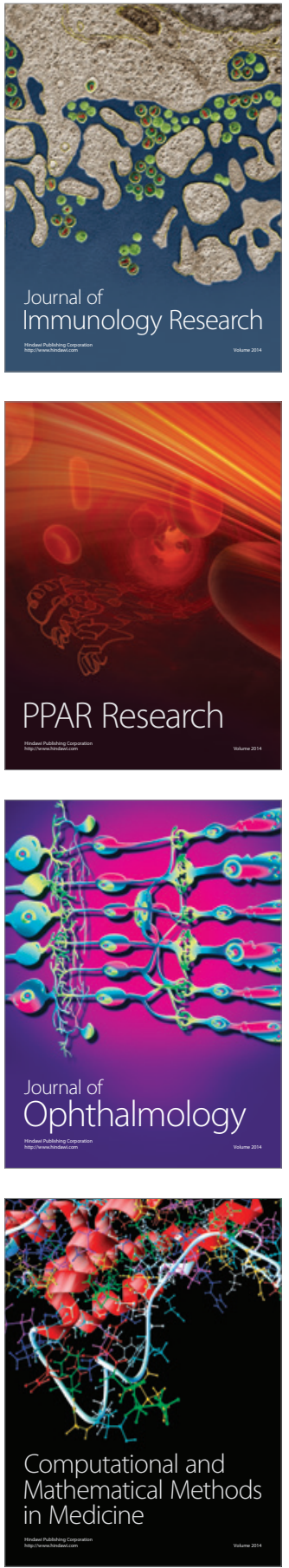

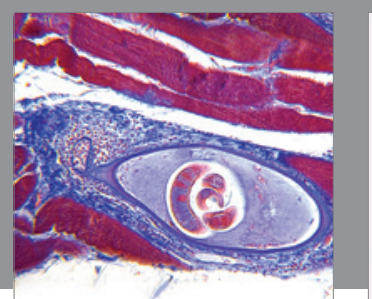

Gastroenterology Research and Practice

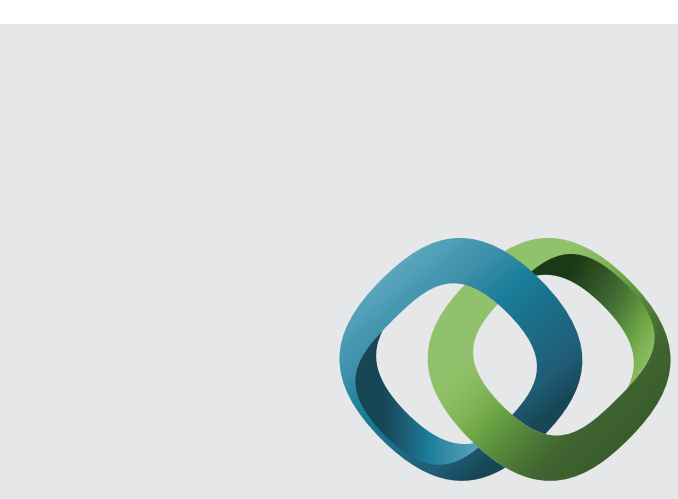

\section{Hindawi}

Submit your manuscripts at

http://www.hindawi.com
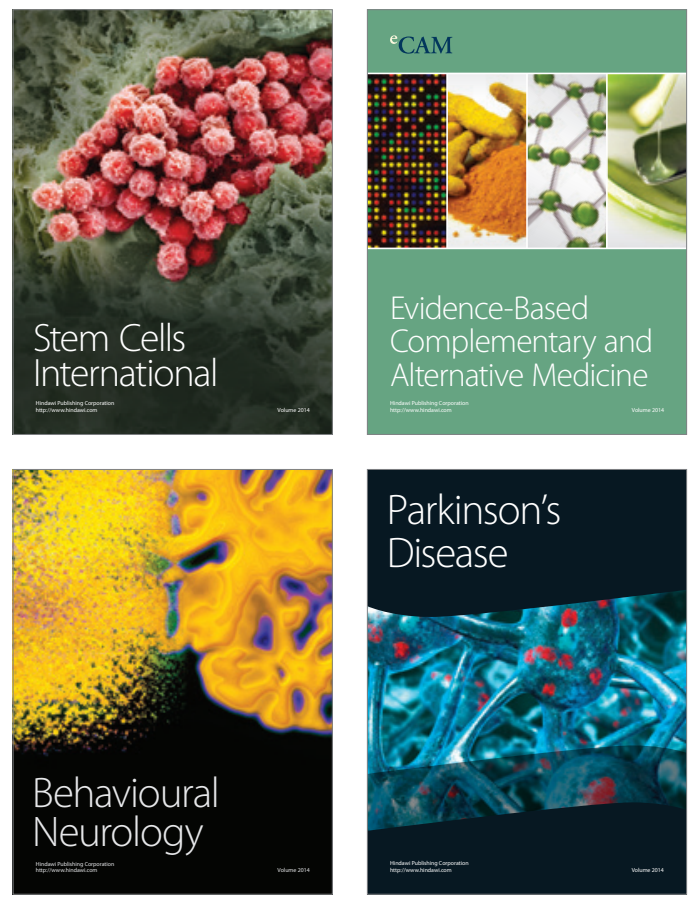
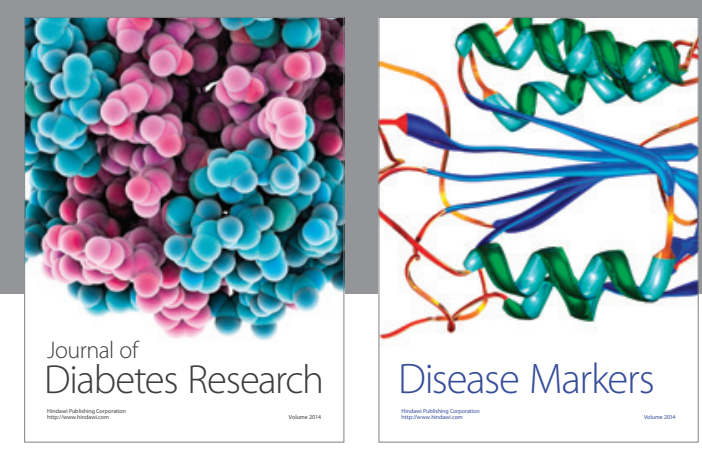

Disease Markers
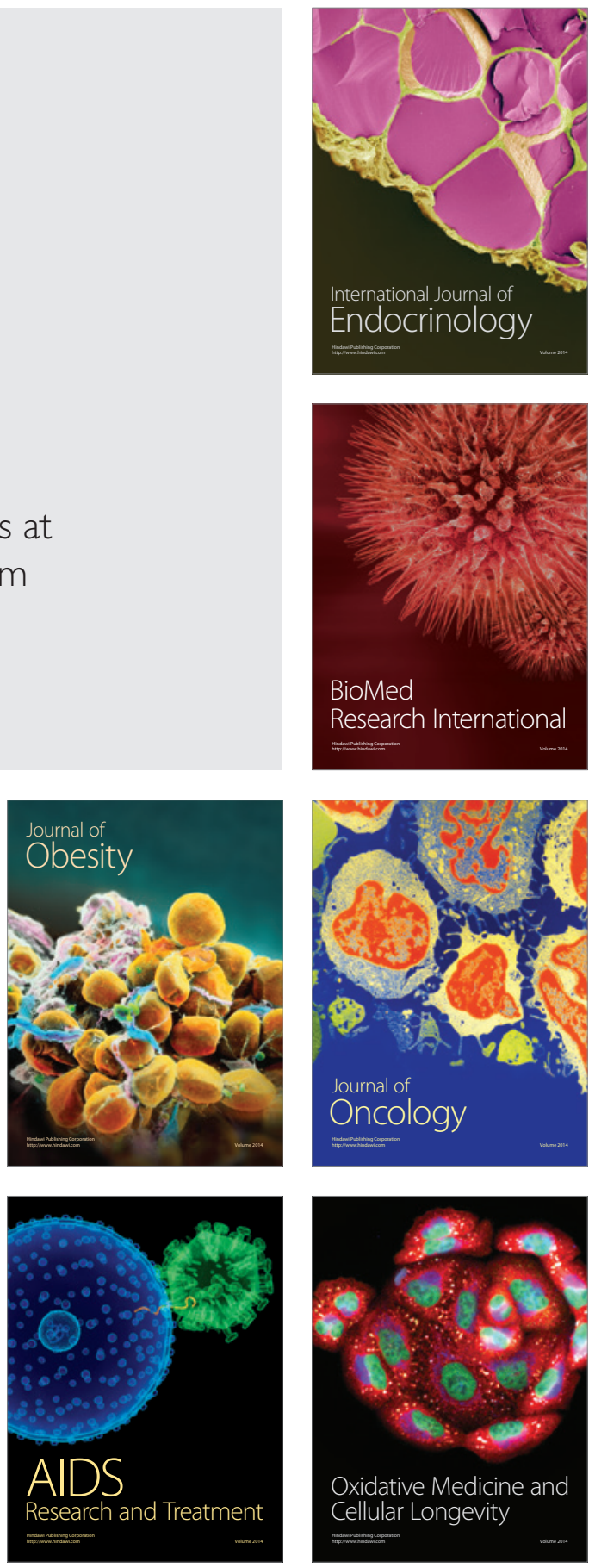